\title{
əOn the Sensitivity of Hurricane Intensity and Structure to Horizontal Tracer Advection Schemes in FV3
}

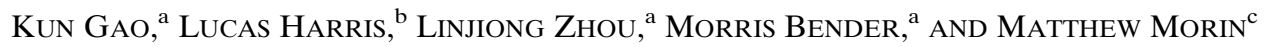 \\ ${ }^{\text {a }}$ Program in Atmospheric and Oceanic Sciences, Princeton University, Princeton, New Jersey \\ ${ }^{\mathrm{b}}$ NOAA/Geophysical Fluid Dynamics Laboratory, Princeton, New Jersey \\ ${ }^{\mathrm{c}}$ University Corporation for Atmospheric Research, Boulder, Colorado
}

(Manuscript received 31 October 2020, in final form 7 July 2021)

\begin{abstract}
We investigate the sensitivity of hurricane intensity and structure to the horizontal tracer advection in the Geophysical Fluid Dynamics Laboratory (GFDL) Finite-Volume Cubed-Sphere Dynamical Core (FV3). We compare two schemes, a monotonic scheme and a less diffusive positive-definite scheme. The positive-definite scheme leads to significant improvement in the intensity prediction relative to the monotonic scheme in a suite of 5-day forecasts that mostly consist of rapidly intensifying hurricanes. Notable storm structural differences are present: the radius of maximum wind (RMW) is smaller and eyewall convection occurs farther inside the RMW when the positive-definite scheme is used. Moreover, we find that the horizontal tracer advection scheme affects the eyewall convection location by affecting the moisture distribution in the inner-core region. This study highlights the importance of dynamical core algorithms in hurricane intensity prediction.
\end{abstract}

KEYWORDS: Tropical cyclones; Numerical weather prediction/forecasting; Numerical analysis/modeling

\section{Introduction}

Hurricanes cause significant damage each year, but the prediction of hurricane intensity still remains a challenging issue. It has long been known that hurricane intensity changes involve interactions of the storm and its environment (synoptic-scale atmospheric flow and the ocean), and also complex storm-scale processes. Developing skillful hurricane prediction systems requires a good understanding of the sensitivity of simulated hurricanes to various model components.

The impact of subgrid physical parameterizations (such as the surface exchange coefficients, boundary layer mixing, convection, microphysics, and radiation) on hurricane intensity and structure has been extensively studied (e.g., Bao et al. 2012; Bryan 2012; Smith et al. 2014; Gopalakrishnan et al. 2012, 2013; McFarquhar et al. 2006; Willoughby et al. 1984). Particularly, the impact of parameterized subgrid diffusion in both the horizontal and vertical directions on hurricane structure and intensity is relatively well understood, thanks to extensive research done with a hierarchy of models. There is broad agreement that, at least in idealized settings, weaker horizontal diffusion, and weaker vertical diffusion in the boundary layer both favor faster storm intensification and smaller inner-core size (Bryan 2012; Gopalakrishnan et al. 2013; Rotunno and Bryan 2012; Zhang and Marks 2015).

In contrast, the sensitivity of simulated hurricanes to the numerical algorithms governing the resolvable components of the atmospheric flow (commonly referred to as the dynamical core) is often overlooked. Here we present an effort to address

¿ Denotes content that is immediately available upon publication as open access.

Corresponding author: Kun Gao, kun.gao@noaa.gov the impact of dynamical core algorithms on simulated hurricane characteristics. We investigate the sensitivity of hurricane intensity and eyewall structure to the choice of the horizontal tracer advection algorithm in the Geophysical Fluid Dynamics Laboratory (GFDL) Finite-Volume Cubed-Sphere Dynamical Core (FV3). The advection algorithm for tracers is an essential component of the dynamical core, which describes the transportation of tracers (e.g., water vapor and cloud hydrometers) with the resolved flow. As the use of cloud-resolving/cloudpermitting resolution becomes common in hurricane research, it is critical for the advection scheme to handle strong gradients and discontinuities in the tracer fields associated with the explicitly resolved convection. The application of horizontal advection algorithms in hurricane conditions is particularly important as the distribution of water vapor and cloud hydrometers could feed back on the dynamics of hurricanes through the parameterized microphysical processes.

We discuss the impact of two horizontal tracer advection schemes available in FV3 (Harris et al. 2020): one uses the monotonicity constraint (Lin 2004), and the second is a less diffusive positive-definite scheme that does not use the monotonic constraint (see the appendix). Harris et al. (2020) presented one example showing that the use of the positivedefinite scheme alone improves the forecast of the rapid intensification (RI) of Hurricane Irma (2017) compared against the monotonic scheme. This is an interesting finding since the tracer advection scheme does not directly operate on the dynamical field. Here we expand the test set and document the significant sensitivity of hurricane intensity and eyewall size to the choice of horizontal tracer advection scheme. We also offer explanations for such sensitivity.

The rest of the paper is organized as follows. In section 2, we outline the model configuration and two sets of 5-day forecasts that only differ in the choice of horizontal tracer advection scheme. In section 3, we compare the model performance in 
intensity prediction in the two sets of experiments. In section 4, we identify important differences in the storm structure between the two experiments. In section 5, we present the design and results of more strictly controlled experiments to reveal the immediate impact of horizontal tracer advection scheme on the radial location of eyewall convection. Finally section 6 presents a summary.

\section{Method}

\section{a. Model overview}

The model used here is a two-way nested configuration of the GFDL System for High-resolution prediction on Earth-toLocal Domains (SHiELD hereafter; Harris et al. 2020). The SHiELD model adopts the nonhydrostatic FV3 and a suite of physical parameterization originated from the operational GFS and further developed at GFDL (Chen et al. 2019; Zhou et al. 2019; Harris et al. 2020).

FV3 has flexible regional refinement capacity (Harris and Lin 2013; Harris et al. 2016) that allows for high-resolution applications. The configuration used in this study is featured with a static nest covering the tropical North Atlantic (Fig. 1), designed for North Atlantic hurricane track and intensity prediction. This configuration of SHiELD is referred to as T-SHiELD to emphasize its application in the tropical region (previously known as hfvGFS). The mean gridcell width is approximately $13 \mathrm{~km}$ for the global grid and $3 \mathrm{~km}$ for the nested grid. In the current configuration, both the global and nested grids use 63 vertical levels.

For the present study, we use the GFDL single-moment sixcategory microphysics scheme (Zhou et al. 2019), which features thermodynamic consistency with the FV3, moist energy conservation, a fast and efficient sedimentation algorithm, and heat and momentum transports during the sedimentation process. Other parameterizations include the Yonsei University (YSU) boundary layer scheme (Hong et al. 2006), the scale-aware deep and shallow convection parameterization (Han et al. 2017), and the Rapid Radiative Transfer Model for GCMs (RRTMG; Iacono et al. 2008) radiation scheme. The deep convection parameterization is enabled in the global domain but disabled in the $3-\mathrm{km}$ nest. The model also uses a simple mixed layer-ocean model (Pollard et al. 1973) to simulate the SST cooling under hurricanes.

\section{b. Horizontal tracer advection scheme}

The horizontal advection in FV3 is done along Lagrangian surfaces based on the two-dimensional advection operator (Lin and Rood 1996; Putman and Lin 2007), while the vertical advection is implicit following Lagrangian surfaces (Lin 2004). FV3 has a number of tracer advection algorithm options, ${ }^{1}$ and in the present study we focus on two schemes commonly used in recent applications of FV3, a monotonic scheme and a newly released positive-definite scheme. Both schemes locally

\footnotetext{
${ }^{1}$ https://www.gfdl.noaa.gov/wp-content/uploads/2020/02/FV3Technical-Description.pdf.
}

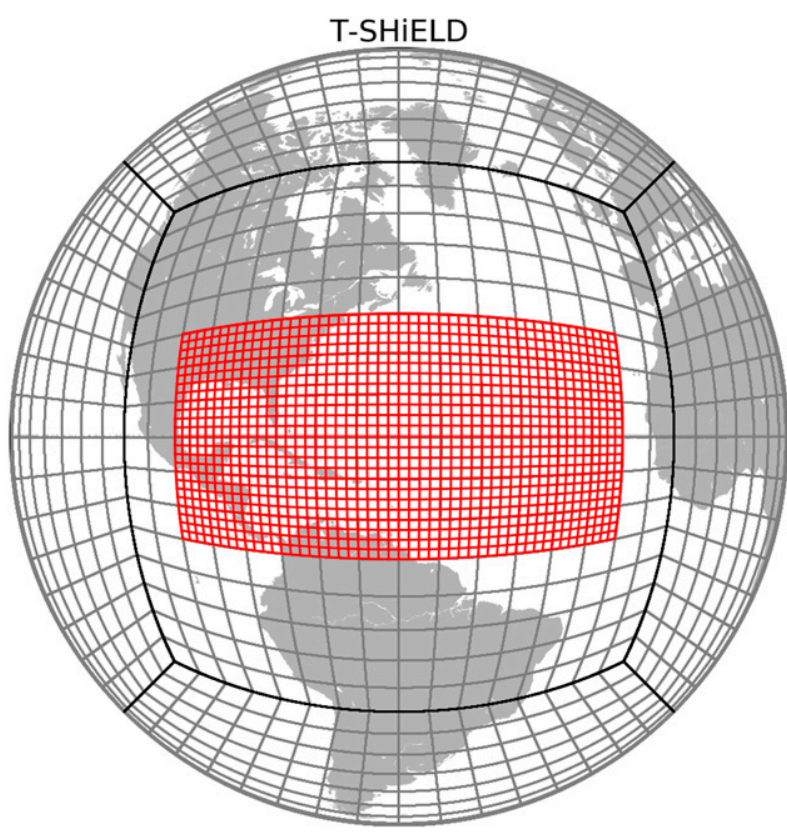

FIG. 1. Grid layout of the two-way nested T-SHiELD system. Each plotted cell represents $48 \times 48$ actual grid cells. Heavy black lines represent cubed-sphere edges; red lines represent nested grids. The horizontal resolution is about $13 \mathrm{~km}$ in the global tile and $3.25 \mathrm{~km}$ in the nest (a refinement ratio of 4 is applied).

conserve tracer mass and ensure positivity of tracer values; their main difference is outlined as follows.

The monotonic tracer advection scheme (MONO hereafter) is based on the piecewise-parabolic method (Collella and Woodward 1984) with the monotonicity constraint described in appendix B of Lin (2004) so that no new extrema in the tracer fields are created by horizontal advections. In nonhydrostatic FV3, the monotonicity constraint has been relaxed for dynamical quantities (vorticity, potential temperature, and air mass), but is still maintained for tracer advection to avoid negative tracer values. The MONO scheme prevents the occurrence of spurious oscillations, but can be overly diffusive in some circumstances.

In contrast to the MONO scheme, the positive-definite scheme (PD hereafter) is designed for improving the representation of marginally resolved and discontinuous features and ensures the positivity of tracer values, but does not impose the monotonicity constraint. The formulation details are given in appendix A of Harris et al. (2020).

\section{c. Five-day forecasts}

We conducted two sets of 5-day forecasts using model configurations that only differ in the choice of the tracer advection schemes in order to reveal their impact on hurricane intensity prediction. The first set of forecasts uses MONO tracer advection scheme and the second uses the PD scheme. The tracers being advected include the water vapor and five hydrometer species: i.e., cloud water, rain, cloud ice, snow, and graupel. 


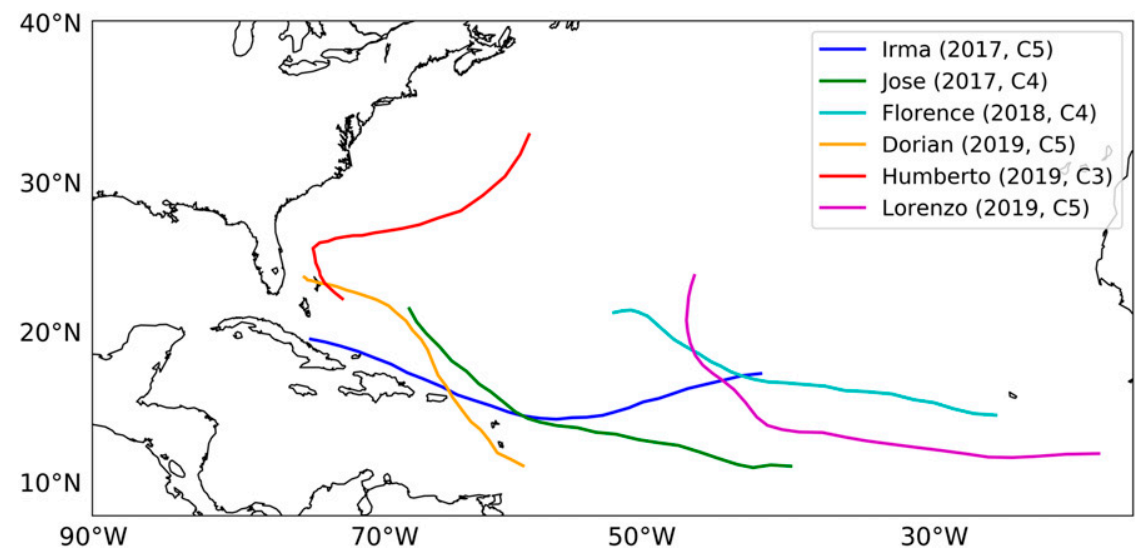

FIG. 2. Observed tracks of the six major hurricanes covered by the 5-day forecasts. The year and their intensity category are indicated in the legend. The observations are from the best track dataset (Landsea and Franklin 2013).

We focus on how the tracer advection scheme affects the intensification processes (particularly RI of major hurricanes) in the present study and the underlying mechanism. Therefore, we choose to consider six noteworthy major hurricanes (Fig. 2) that occurred in the 2017-19 Atlantic seasons in our test set, of which three reached category 5 intensity, and five underwent RI (defined as intensity change exceeding $30 \mathrm{kt}$ over $24 \mathrm{~h} ; 1 \mathrm{kt} \approx 0.51 \mathrm{~m} \mathrm{~s}^{-1}$ ). Although Hurricane Humberto (2019) did not undergo RI, it showed impressive steady intensification during much of its lifetime, making it a good test case. Hurricane Florence (2018) underwent two intensification periods. Its intensity reached the first peak at 1800 UTC 5 September 2018 and then weakened due to the impact of strong vertical wind shear. The storm underwent $\mathrm{RI}$ again and reached its lifetime maximum intensity on 1800 UTC 11 September 2018. Here we only consider the first intensification period.

We conduct eight runs for each selected storm, initialized $6 \mathrm{~h}$ apart (Table 1), which covers the period during which the storm intensifies from a relatively weak system to its peak intensity. Each run is initialized at least $60 \mathrm{~h}$ prior to the time when the storm reached peak intensity. The initial conditions for these runs are remapped from operational NCEP GFS analyses. In total, 48 forecasts were conducted. Such sample size is probably not sufficiently large for a comprehensive hurricane track and intensity forecast error verification, which usually requires multiyear samples. However, the sample here should be sufficient for the purpose of the present study, since we focus on exploring the sensitivity of hurricane intensity and structure to the horizontal tracer advection scheme and also the underlying mechanism.

Additional short-duration warm-start experiments are conducted to interpret the results from the 5-day forecasts. The motivation and the detailed design of these warm-start experiments will be given in section 5 .

\section{d. Composite analysis}

Composite analysis is applied throughout this paper to identify key differences in the storm structure caused by the choices of the tracer advection scheme. Here we give a brief description on the procedures for obtaining the composite azimuthal-mean structure. As a first step, we subtract the environmental wind, calculated as the wind averaged over the $6^{\circ} \times 6^{\circ}$ area centered around the storm center, from the total wind field to obtain the hurricane wind field. Then the horizontal hurricane wind fields are projected onto the storm-relative cylindrical coordinates to obtain the radial and tangential wind components. The azimuthal-mean structure is obtained next; when performing azimuthal averaging, the radial bin width is set equal to the model grid spacing. Each azimuthal-averaged snapshot is mapped onto the normalized radius, i.e., the actual radius divided by the instantaneous radius of maximum wind (RMW) determined from the azimuthal-mean 10-m height wind speed. Finally, the multistorm composite averaging can be done for selected azimuthal-averaged snapshots.

\section{Intensity verification}

We begin our analysis with evaluating the model intensity prediction skill (Fig. 3) in the two sets of 5-day forecasts, measured by the mean bias and mean absolute error of the two intensity parameters, i.e., the maximum 10-m height wind $\left(V_{\max }\right)$ and minimum sea level pressure $\left(P_{\min }\right)$. The track verification is not shown because the differences in the track errors between the two sets of forecasts are small. For many cases the two experiments have indistinguishable tropical cyclone (TC) tracks. In average the PD experiments have degraded track performance $(-5 \%$ at day 3 and $-8.5 \%$ at day 5$)$ compared to the MONO experiments, but the differences are not statistically significant at the $95 \%$ level. $^{2}$

\footnotetext{
${ }^{2}$ We would like to clarify here that the use of the PD scheme is not a source of model track error. The recent versions of near-realtime T-SHiELD system (2020 and 2021 versions) used the PD scheme as the default choice and showed consistent better track skill than the operational Global Forecast System in retrospective multiseason samples.
} 
TABLE 1. List of the storms covered by the two sets of 5-day forecasts, their peak intensity in the 6-hourly best track dataset ("cat." indicates category on the Saffir-Simpson scale), and the model initialization time.

\begin{tabular}{lcl}
\hline \hline \multicolumn{1}{c}{ Storm name } & Maximum intensity & \multicolumn{1}{c}{ Initial time (every 6h) } \\
\hline Irma (2017) & $82.3 \mathrm{~m} \mathrm{~s}^{-1}$, cat. 5 & 0000 UTC 2 Sep-1800 UTC 3 Sep \\
Jose (2017) & $69.5 \mathrm{~m} \mathrm{~s}^{-1}$, cat. 4 & 1800 UTC 4 Sep-1200 UTC 6 Sep \\
Florence (2018) & $59.2 \mathrm{~m} \mathrm{~s}^{-1}$, cat. 4 & 1800 UTC 31 Aug-1200 UTC 2 Sep \\
Dorian (2019) & $82.3 \mathrm{~m} \mathrm{~s}^{-1}$, cat. 5 & 0600 UTC 27 Aug-0000 UTC 29 Aug \\
Humberto (2019) & $54.0 \mathrm{~m} \mathrm{~s}^{-1}$, cat. 3 & 1200 UTC 13 Sep-0600 UTC 15 Sep \\
Lorenzo (2019) & $69.5 \mathrm{~m} \mathrm{~s}^{-1}$, cat. 5 & 0600 UTC 23 Sep-0000 UTC 25 Sep \\
\hline
\end{tabular}

For both configurations, the mean wind intensity bias becomes negative at lead times beyond the first day, and the magnitude of the bias continues to increase until a lead time of $96 \mathrm{~h}$ (Fig. 3). This indicates the model struggles to predict the actual intensification rates of those storms to some extent regardless of the tracer advection scheme used. The magnitude of intensity bias generally reduces at day 5 when the observed storms weaken in a significant portion of the analyzed forecast period.

Nevertheless, we would like to emphasize the difference between the two sets of forecasts. The negative bias in PD experiments on average is much smaller than that in the MONO experiments, with the largest differences evident at longer lead times (significant at $95 \%$ level beyond $48 \mathrm{~h}$ ). The magnitude of the intensity bias in the PD experiments is at least
$50 \%$ smaller than that in the MONO experiments at lead times beyond $24 \mathrm{~h}$. Consistent with the mean bias verification, the mean absolute intensity errors (as indicated by $V_{\max }$ and $P_{\min }$ verifications in Fig. 3) in the PD experiments are also substantially smaller than in the MONO experiments.

The intensity verification above indicates that when the PD advection scheme is used, the predicted hurricanes in this study reach a stronger and more realistic intensity. To illustrate the difference in the two configurations, we show the intensity forecasts from a few representative cases in Fig. 4, along with the time variation of RMW. Since there are no reliable observations of the RMWs, we only show the model values. The forecasts using the PD advection scheme consistently predict more realistic intensification processes, and the model storms eventually reach a lifetime maximum intensity closer to what
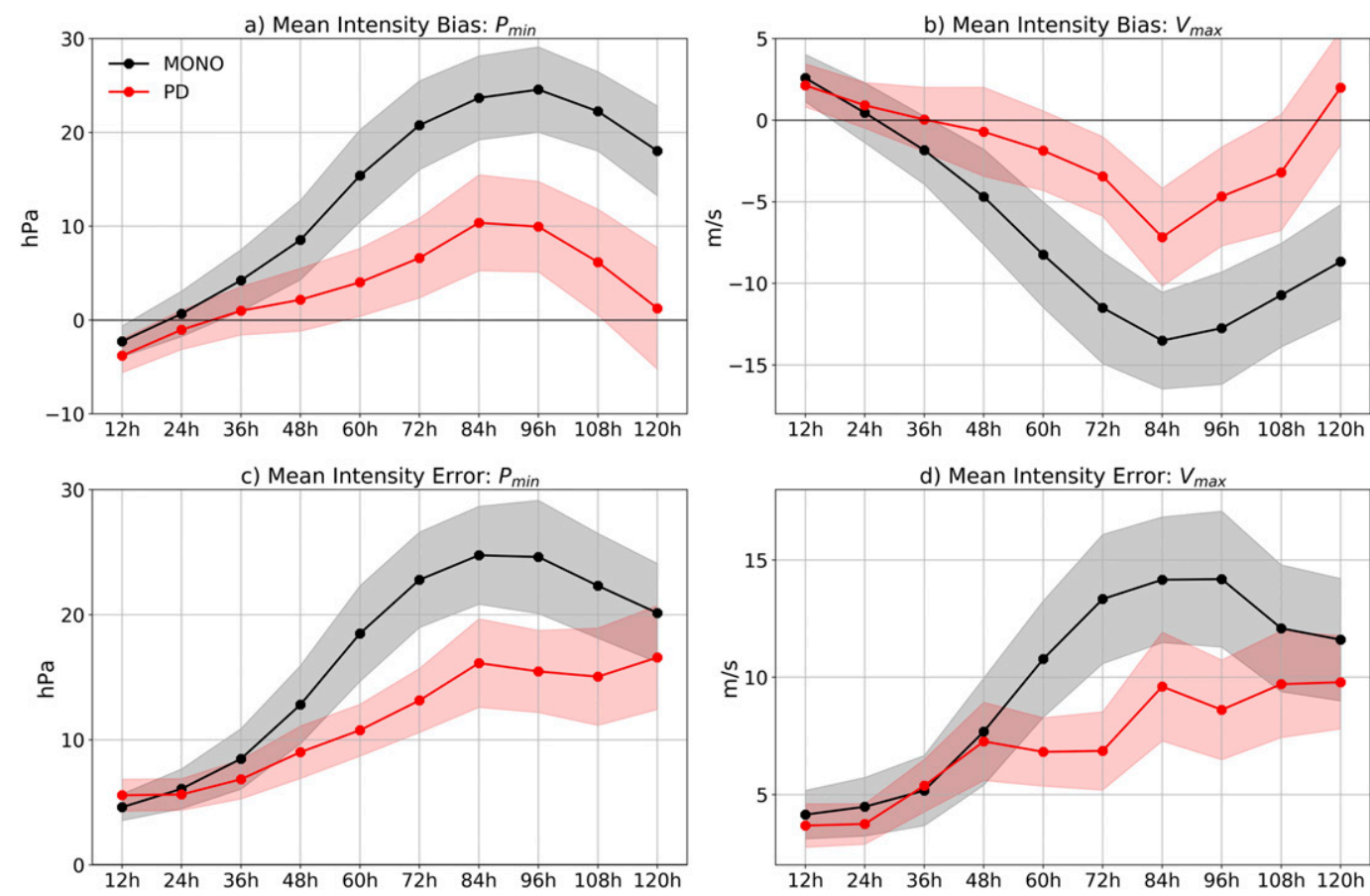

FIG. 3. Verification of the intensity forecast from the two sets of 5-day forecasts using monotonic (MONO) and positive-definite (PD) horizontal tracer advection schemes, respectively. The number of cases is 48 throughout the 5-day period. (a),(b) Mean intensity bias as indicated by the minimum sea level pressure $\left(P_{\min }\right)$ and maximum 10-mheight wind speed $\left(V_{\max }\right)$, respectively. (c),(d) As in (a) and (b), but for the mean absolute intensity error. The shaded areas represent the $95 \%$ confidence level. 

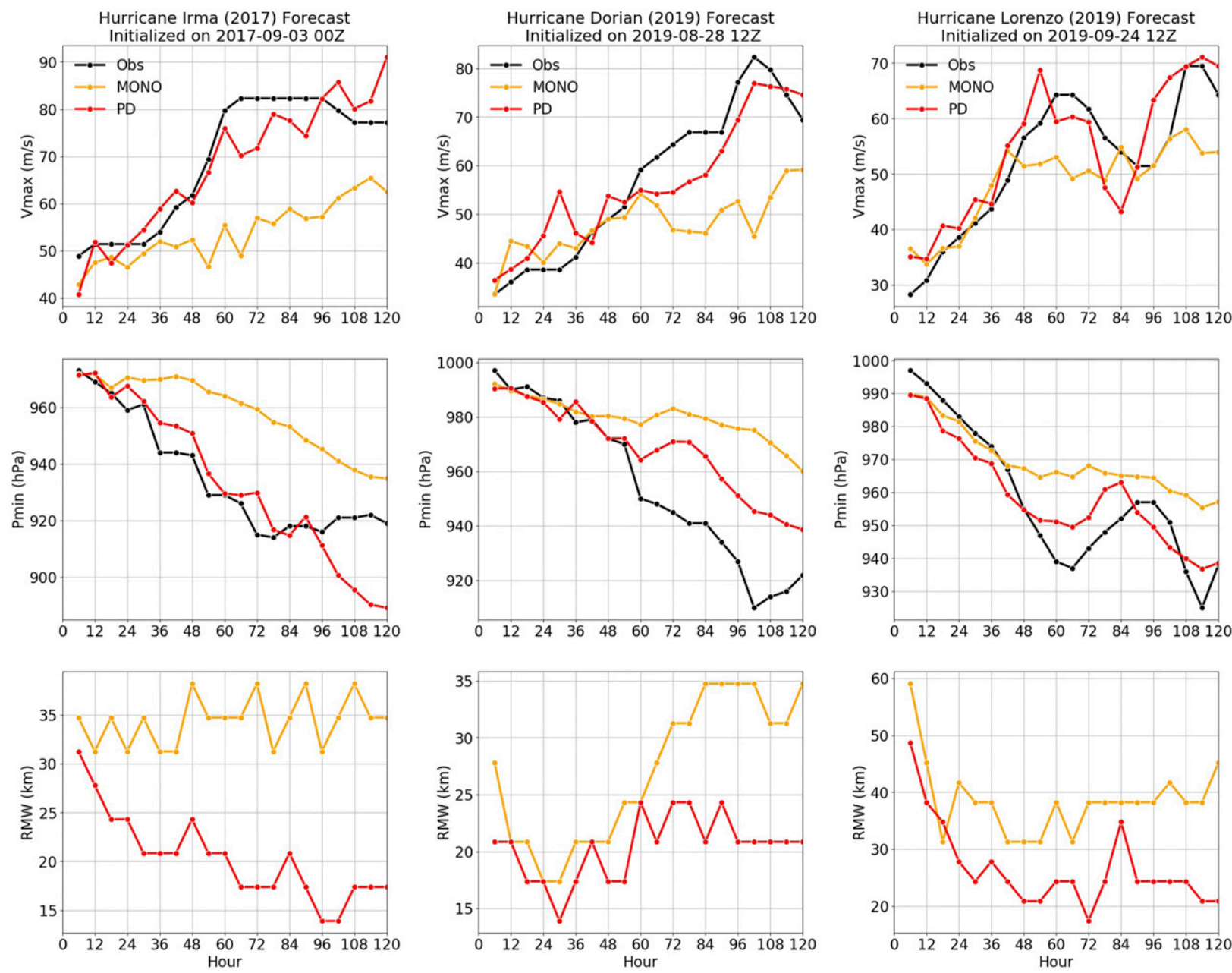

FIG. 4. Prediction of three major hurricanes from the 5-day forecasts using MONO and PD schemes, respectively. (left) Irma (2017), (center) Dorian (2019), and (right) Lorenzo (2019). (top) The maximum 10-m-height wind, (middle) the minimum sea level pressure, and (bottom) the radius of maximum wind. The predicted storm intensity is compared against best track data (black).

was observed. The MONO forecasts tend to underpredict the intensification rate and the storm lifetime maximum intensity. Interestingly, we notice that the PD experiment successfully predicts the eyewall replacement cycle (ERC) of Hurricane Lorenzo (Fig. 4; as indicated by the two peaks in $V_{\max }$ ) a few days in advance, while the MONO experiment does not. The impact of tracer advection on the prediction of ERC is not a main focus of the present study, but warrants further investigation.

The storms in PD forecasts generally develop smaller eyes as the storms intensify than in the MONO forecasts, as indicated by the RMW time series in Fig. 4. This itself is not a surprising result because as shown in other modeling studies (e.g., Gopalakrishnan et al. 2013) stronger storms are generally associated with smaller RMWs. We will show in section 4 that even for the same intensities, the PD simulations produce storms with smaller RMWs.

The results discussed so far reinforce the findings reported in Harris et al. (2020), who only examined the prediction of
Irma (2017) as a case study. In this work we find that the use of the PD scheme consistently produces more rapidly intensifying storms with stronger lifetime maximum intensity and substantially reduces the model intensity error in the test set. The large-scale environment and the hurricane tracks in the two sets of forecasts are similar (not shown). Therefore, the difference in intensity must be related to the storm-scale processes. In the following section, we proceed to examine the storm structure to help interpret the intensity difference between the two sets of forecasts.

\section{Structural difference}

\section{a. Radius of maximum wind}

We have shown in section 3 that, while achieving a stronger intensity, the predicted storms in the PD experiments generally have smaller RMWs than those in the MONO experiments. We next show that even with comparable intensity, the RMW 


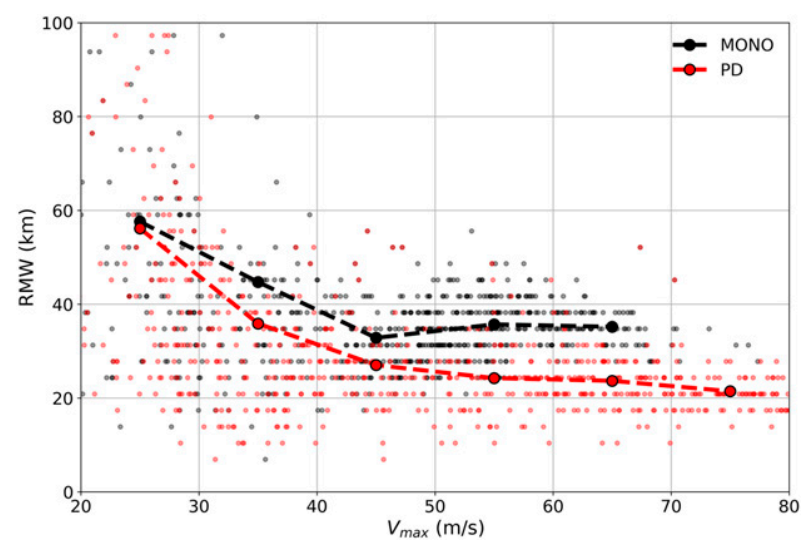

FIG. 5. The radius of maximum wind (RMW) determined from the azimuthal-mean 10-m-height wind speed. The scattered smallsize dots show all 6-hourly RMW records from the two experiments. The dashed line with solid dots shows the bin-averaged RMW from consecutive $10 \mathrm{~m} \mathrm{~s}^{-1}$ intensity brackets (e.g., 20$30 \mathrm{~m} \mathrm{~s}^{-1}, 30-40 \mathrm{~m} \mathrm{~s}^{-1}$, and so on). The bin-averaged value in 70 $80 \mathrm{~m} \mathrm{~s}^{-1}$ range is not shown for MONO cases due to the limited sample size.

in the PD experiments is noticeably smaller. Figure 5 shows all the 6-hourly RMW records determined from the two sets of 5-day runs. To better reveal the difference between the two experiments, we calculated the bin-averaged RMW in each $10 \mathrm{~m} \mathrm{~s}^{-1}$ intensity brackets $\left(20-30 \mathrm{~m} \mathrm{~s}^{-1}, 30-40 \mathrm{~m} \mathrm{~s}^{-1}\right.$, and so on). The difference is most significant in the major hurricane intensity range $\left(V_{\max }\right.$ larger than $\left.50 \mathrm{~m} \mathrm{~s}^{-1}\right)$. The instantaneous RMW values rarely become smaller than $20 \mathrm{~km}$ in the MONO experiments, as opposed to the PD cases, where the RMW can shrink to half that size. On average RMW in PD cases is approximately 30\% smaller than MONO cases in the intensity range beyond $50 \mathrm{~m} \mathrm{~s}^{-1}$ (34.3 vs $24.3 \mathrm{~km})$.

Our analysis indicates that the use of the PD scheme favors a more compact eye even for storms with similar intensity. This is a noteworthy finding considering the only difference between the two sets of runs is the choice of horizontal advection scheme, and other factors that could affect RMW (such as the horizontal resolution, explicitly parameterized horizontal and vertical diffusion coefficients) are not varied. To our knowledge, such significant sensitivity of simulated hurricane intensity and eye size to the dynamical-core algorithms has not been previously reported.

\section{b. Composite wind structure}

We next examine differences in the composite wind structure between the two experiments. In the analysis below we focus on the composite of the intensifying period only. Although previous studies suggest that there is certain structural difference between the storm intensification and the quasi-steady states (Rogers et al. 2013), we find the main structural difference (e.g., the mean RMW and relative location of eyewall convection) presented below does not change qualitatively (not shown) for the quasisteady state.
Figure 6 shows the composite azimuthal-mean wind structure for storms in the $40-60 \mathrm{~m} \mathrm{~s}^{-1}$ intensity range during the storm intensification period, in comparison with composites created based on Doppler radar observations collected from 22 different hurricanes over North Atlantic during 1997-2016 (Gao et al. 2019). Figure 7 shows the radial profiles of azimuthal-mean tangential wind and inertial stability parameter $(I)$ at 2-km height (above the frictional boundary layer) to assist the discussion. The inertial stability parameter $(I)$ is calculated as $I=\sqrt{\left(f+V_{t} / r+\partial V_{t} / \partial r\right)\left(f+2 V_{t} / r\right)}$, where $f$ is the Coriolis parameter, $V_{t}$ is the azimuthal-averaged tangential wind, and $r$ is the radius (Kepert 2001). Below we summarize the key points that can be inferred from Figs. 6 and 7.

1) Similar to what found in Gao et al. (2019), there are still some notable inconsistencies between the model and observed composites, despite the higher model horizontal resolution used in the present study. For example, the eyewall updrafts in both configurations are weaker than in observations and the model vertical velocity reaches its maximum value at a level lower than in the radar composites. Nevertheless, the model composite wind fields largely resemble those from observations.

2) The composite tangential wind obtained from the selected intensity range in the two sets of experiments are similar (Figs. 6a,b), except that the averaged RMW in the PD experiments is smaller $(24.3 \mathrm{vs} 34.3 \mathrm{~km})$. This is a desirable setting since we aim to compare the storm structure in the two experiments when the storm intensities are similar. Because RMW is smaller in the PD experiments, $I$ is larger in the inner-core region (Fig. 7a).

3) There is an interesting difference in the radial flow (Figs. 6c,d): the boundary layer inflow layer is shallower and the nearsurface inflow is weaker in the PD composites. Such behavior can be explained by the balanced hurricane boundary layer theory (Kepert 2001). The hurricane boundary layer depth $\delta$ scales with $\sqrt{2 K / I}$, where $K$ is the vertical diffusion coefficient from the BL scheme. The shallower inflow layer in the PD experiment is therefore consistent with the smaller $\delta$ that is largely due to the larger $I$ in the inner-core region. The weaker frictional inflow in the PD experiments can also be attributed to the larger $I$. To first order the frictional inward mass flux is determined by a balance between frictional destruction of absolute angular momentum and its replenishment by radial advection (Kepert 2001). A larger $I$ indicates a stronger radial angular momentum gradient, and therefore, less radial inflow is required to satisfy the above balance provided everything else being equal.

4) Finally, we emphasize that the most interesting difference between the two experiments lies in the eyewall updraft (Figs. 6e,f and Fig. 7b): the peak updraft in the PD experiments locates farther inside of the RMW above the boundary layer, a feature more consistent with observed distribution in Fig. 6i. Considering that the updraft is closely related to the latent heat release associated with the deep convection at higher levels, such a distribution of updraft suggests that the heating also locates farther inward in PD experiments. 

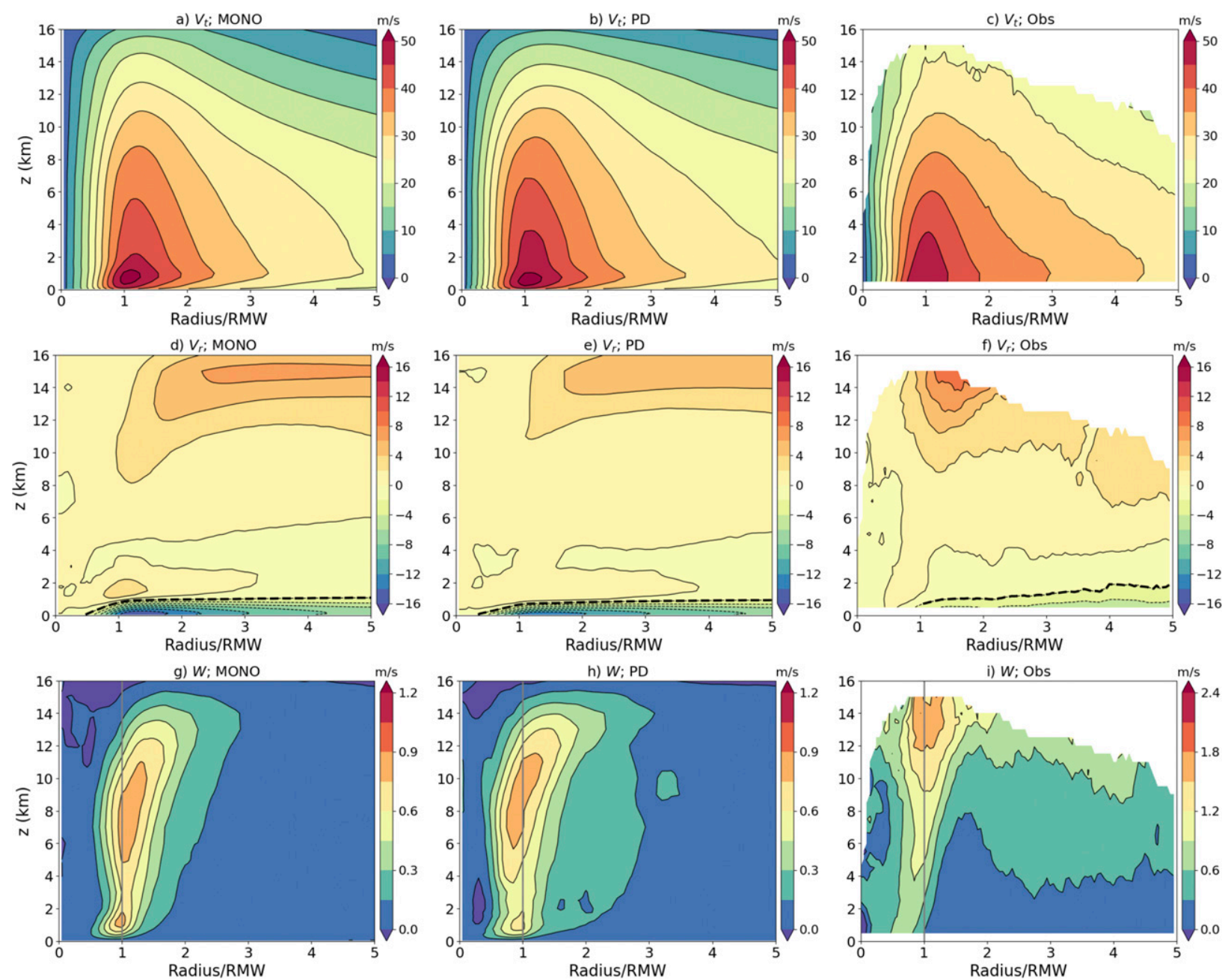

FIG. 6. Composite azimuthal-mean (a)-(c) tangential $\left(V_{t}\right)$, (d)-(f) radial $\left(V_{r}\right)$, and (g)-(i) vertical $(W)$ wind structure along normalized radius from the 5-day (left) MONO and (center) PD forecasts and (right) radar observations (Gao et al. 2019). The model composites are obtained from snapshots in $40-60 \mathrm{~m} \mathrm{~s}^{-1}$ intensity range. The numbers of 6-hourly snapshots used to create the composites are 246 (MONO) and 169 (PD), respectively. The vertical line in (g)-(i) indicates the location of the RMW. Note that the radar composites are based on observations collected in storms different from the list in Table 1.

So far, we have identified a few key differences in the hurricane azimuthal structural between the two experiments. The above analysis indicates that the storms in the PD experiments feature not only smaller RMW (and thus larger $I$ in the inner-core region), but also eyewall deep convection that occurs more radially inward relative to the RMW than in the MONO experiments. These structural differences are critical for understanding the different intensification rates in the two experiments. Previous theories and modeling studies are in consensus that hurricanes intensify more rapidly if that heating locates more inside of the RMW, in the region with stronger inertial stability (e.g., Schubert and Hack 1982; Shapiro and Willoughby 1982; Vigh and Schubert 2009; Smith and Montgomery 2016). Thus, both the higher $I$ in the inner-core region and the more radially inward eyewall convection favor stronger intensification rate and provide an explanation for the stronger storm intensity in the 5-day PD forecasts.

At this point it remains unclear why the eyewall convection locates more radially inward relative to RMW in the PD experiments. Previous studies indicate that the location of eyewall convection is related to the boundary layer convergence caused by the inflow (e.g., Kepert and Nolan 2014), which in turn is regulated by the storm size and inertial stability. According to Kepert (2017), the eyewall updraft is displaced inward of RMW by a distance that scales with $-U_{10 \mathrm{~m}} / I$, where $U_{10 \mathrm{~m}}$ is the 10 -m-height radial inflow. The inward penetration of the eyewall updraft past the RMW should be smaller when the surface inflow is weaker and $I$ is larger. Therefore, the frictional convergence cannot explain the difference in the eyewall convection location between the two experiments in the present study. 

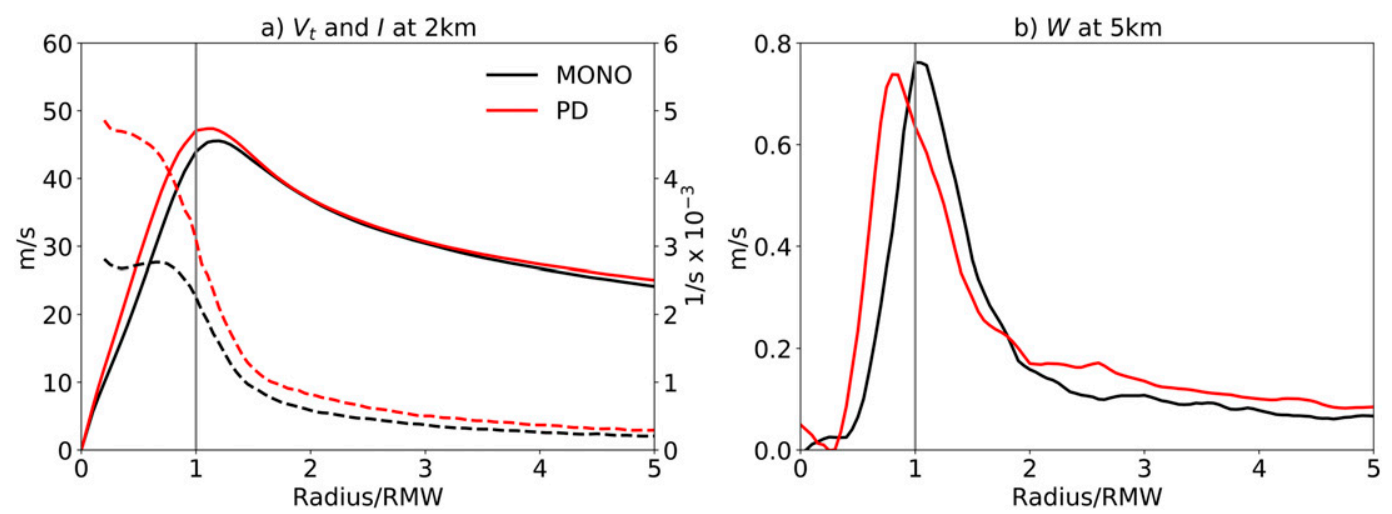

FIG. 7. (a) Composite of azimuthal-mean tangential wind speed (solid) and inertial stability parameter at $2 \mathrm{~km}$ (dashed) along normalized radius. (b) As in (a), but for vertical velocity at 5-km height. The composites are obtained from snapshots in the same intensity range as Fig. 6.

The relative radial location of eyewall convection in the two experiments must be directly or indirectly related to the choice of the tracer advection scheme. The key question to be addressed is as follows: Is the more radially inward eyewall convection in the PD experiments a direct response to the use of the less diffusive tracer advection scheme or simply a manifestation of smaller and more rapidly developing storms? The existing 5-day runs are not ideal for addressing this question because the causality between smaller storm size (RMW) and the radial distribution of deep convection is unclear. We next seek to clarify this relationship through more strictly controlled experiments.

\section{Immediate response of eyewall convection to the tracer advection scheme}

\section{a. Experimental design}

Here we present results from two new groups (a primary and a secondary) of experiments to understand the cause of the more radially inward deep convection in the 5-day PD experiments (summarized in Table 2). The primary group is designed to confirm if the choice of tracer advection scheme can directly affect the location of eyewall convection (particularly the diabatic heating). For this purpose, the primary group is designed with the following requirements.

1) The two experiments that only differ in the choice of tracer advection scheme should start from identical conditions with fully spun-up hurricane dynamical and cloud hydrometer fields.

2) The two experiments should have (nearly) the same horizontal wind fields, including the maximum wind speed and its radial location, so that the changes in tracers (water vapor and hydrometers) and eyewall convection location can be directly attributed to the choice of tracer advection scheme.

With the above considerations, we conduct two sets of warmstart experiments described as follows. As the first step, we save restart files from a few selected PD forecasts cold-started from the relative coarse-resolution GFS analyses at various stages (at least $24 \mathrm{~h}$ after initialization), which are later used as new initial conditions for warm-starting the model ${ }^{3}$ (satisfying the above requirement 1 ). The selected forecasts and the time when the restart files are saved are listed in Table 3. In the second step, a few pairs of experiments that only differ in tracer advection scheme are conducted after being initialized with the restart files saved in the first step. These warm-start runs only integrate forward for $30 \mathrm{~min}$, which seems sufficient for identifying the change of eyewall convection caused by the tracer advection scheme. The storm center location and the horizontal wind fields in any given pair of warm-start experiments are nearly the same (satisfying our requirement 2). We save high frequency (3-min interval) three-dimensional fields for analysis. In total 10 pairs of warm-start experiments are conducted. The sample size (10) here seems sufficient as we find the results from the 10 pairs of runs are consistent. To distinguish from the 5-day forecasts analyzed in previous sections, we labeled these new warm-start runs as PD_warmstart and MONO_warmstart, ${ }^{4}$ respectively.

In the second group of experiments, we introduce a passive tracer that resembles the water vapor mixing ratio $\left(q_{v}\right)$ and only vary the choice of horizontal tracer advection scheme for the passive tracer. The two experiments (labeled as PD_passive and MONO_passive, respectively) have exactly the same settings as PD_warmstart experiments described above and therefore have the identical horizontal and vertical flow as PD_warmstart experiments. The only change is that we introduced a passive tracer that has the

\footnotetext{
${ }^{3}$ The two tracer advection schemes differ in the degree of implicit diffusion. Considering that diffusion is an irreversible process, we choose to save the restart files from the forecasts using the less diffusive positive-definite scheme.

${ }^{4}$ The PD_warmstart experiments simply reproduce the results of the spinup runs but with more variables in the outputs at a higher frequency.
} 
TABLE 2. Description of the two groups of warm-start experiments.

\begin{tabular}{clccc}
\hline \hline Group & \multicolumn{1}{c}{ Expt name } & $\begin{array}{c}\text { Advection scheme } \\
\text { for active tracers }\end{array}$ & $\begin{array}{c}\text { Advection scheme } \\
\text { for the passive tracer }\end{array}$ & Description of the dynamical field \\
\hline Primary & PD_warmstart & PD & MONO & $\begin{array}{c}\text { Storms have the same center location and } \\
\text { RMW, and nearly the same horizontal } \\
\text { flow; the difference is triggered by the } \\
\text { change of active tracers }\end{array}$ \\
Secondary & PD_passive & PD & PD & PD \\
& MONO_passive & MONO & $\begin{array}{c}\text { All fields are identical except for the } \\
\text { passive tracer }\end{array}$ \\
\hline
\end{tabular}

same three-dimensional distribution as $q_{v}$ at initialization. The $q_{v^{-}}$ like tracer is only passively advected and there is no feedback on the dynamical field and other tracers. The distribution of the $q_{v^{-}}$ like passive tracer thus gives an indication of what the distribution of actual $q_{v}$ would be without phase changes.

\section{b. Implicit diffusion as seen in instantaneous tracer fields}

Here we briefly present a few snapshots of the instantaneous tracer fields to get an impression of the implicit diffusion associated with the two tracer advection schemes. Figure 8 shows the instantaneous specific humidity and cloud liquid water mixing ratio fields after 30-min of integration from the MONO_warmstart and PD_warmstart experiments. The overall distribution of water vapor, the location of eyewall convection, and the outer-region convection in the two experiments remain similar. But it is noticeable that the tracer fields are featured with sharper boundaries and stronger gradients in the PD_warmstart experiment. The use of the monotonicity constraint in the MONO_warmstart experiment prevents the occurrence of spurious oscillations, but may have caused excessive smoothing in the tracer distributions.

\section{c. Change of the eyewall convection}

We next turn our attention to the change of eyewall convection in PD_warmstart and MONO_warmstart experiments. The tracer advection scheme operates in all model layers and determines the three-dimensional distribution of

TABLE 3. Storm information at the time when the restart files are saved in the two spinup runs.

\begin{tabular}{lccc}
\hline $\begin{array}{c}\text { Initial time of the } \\
\text { spinup run }\end{array}$ & $\begin{array}{c}\text { Elapsed time when } \\
\text { restart files are } \\
\text { saved }(\mathrm{h})\end{array}$ & $\begin{array}{c}V_{\max } \\
\left(\mathrm{m} \mathrm{s}^{-1}\right)\end{array}$ & $\begin{array}{c}\text { RMW } \\
(\mathrm{km})\end{array}$ \\
\hline Irma (2017), 0000 UTC & 24 & 50.1 & 24.1 \\
3 Sep 2017 & 36 & 59.3 & 20.9 \\
& 48 & 60.2 & 24.1 \\
& 60 & 76.5 & 20.9 \\
Lorenzo (2019), 0000 UTC & 72 & 72.1 & 17.6 \\
24 Sep 2019 & 24 & 42.6 & 24.6 \\
& 36 & 46.1 & 20.6 \\
& 48 & 55.1 & 24.6 \\
& 60 & 62.4 & 20.6 \\
& 72 & 66.0 & 20.6 \\
\hline
\end{tabular}

water vapor and the five hydrometer species, which in turn affects microphysical processes. In our following analysis, we focus on the distribution of the net diabatic heating from the microphysics scheme instead of individual water species. Considering the apparent difference in RMW and eyewall updraft presented in section 4 , it is reasonable to assume there must be some systematic difference in eyewall convection that can be revealed from composite analysis of the azimuthal-mean fields.

We find that the difference in eyewall convection between the two sets of primary warm-start experiments quickly establishes. Figures 9 and 10 illustrate the composite azimuthal-mean diabatic heating from the GFDL microphysics scheme and vertical velocity field obtained from the 30-min warm-start experiments, along with the composites of their differences. Hereafter we use the term "change" (denoted by $\delta$ ) to refer to the differences in the hurricane structure between the experiments using PD and MONO schemes.

The change of diabatic heating $(H)$ and vertical velocity $(W)$ fields with the tracer advection scheme are evident (Fig. 9). The $H$ is stronger inside of RMW and weaker outside of RMW almost throughout the column (Fig. 9c; Fig. 10b) in the PD_ warmstart experiments. The change in the $W$ field (Figs. 9f, 10d) shows a similar pattern, which is expected since the change of heating directly affects the buoyancy and hence the magnitude of the vertical flow. Note that the horizontal flow (including the maximum wind and its radius) in the two warmstart experiments is largely the same. Thus, the warm-start experiments here indicate that the application of the PD scheme on tracers is directly responsible for the more radially inward eyewall convection.

\section{d. Interpretation of eyewall convection change}

The pattern of $\delta H$ presented in Fig. 9c is by no means easy to interpret since it is a net result from interlinked microphysical processes. Below we aim to provide a simplified view of how the change of tracer advection scheme leads to the dipole pattern of $\delta H$ aided by the passive tracer experiments.

Considering the pattern of $\delta H$ (Fig. 9c) is vertically coherent, it is reasonable to assume that the change of $H$ is initiated at certain levels due to the change of tracer distribution (either water vapor or the cloud condensates) and then propagates upward with the vertical flow. The moisture content in the inner-core region is at the heart of the eyewall convection, and we therefore pay attention to the change of $q_{v}$ in the warm-start runs (Figs. 11a-c). The $\delta q_{v}$ field in the warm-start 

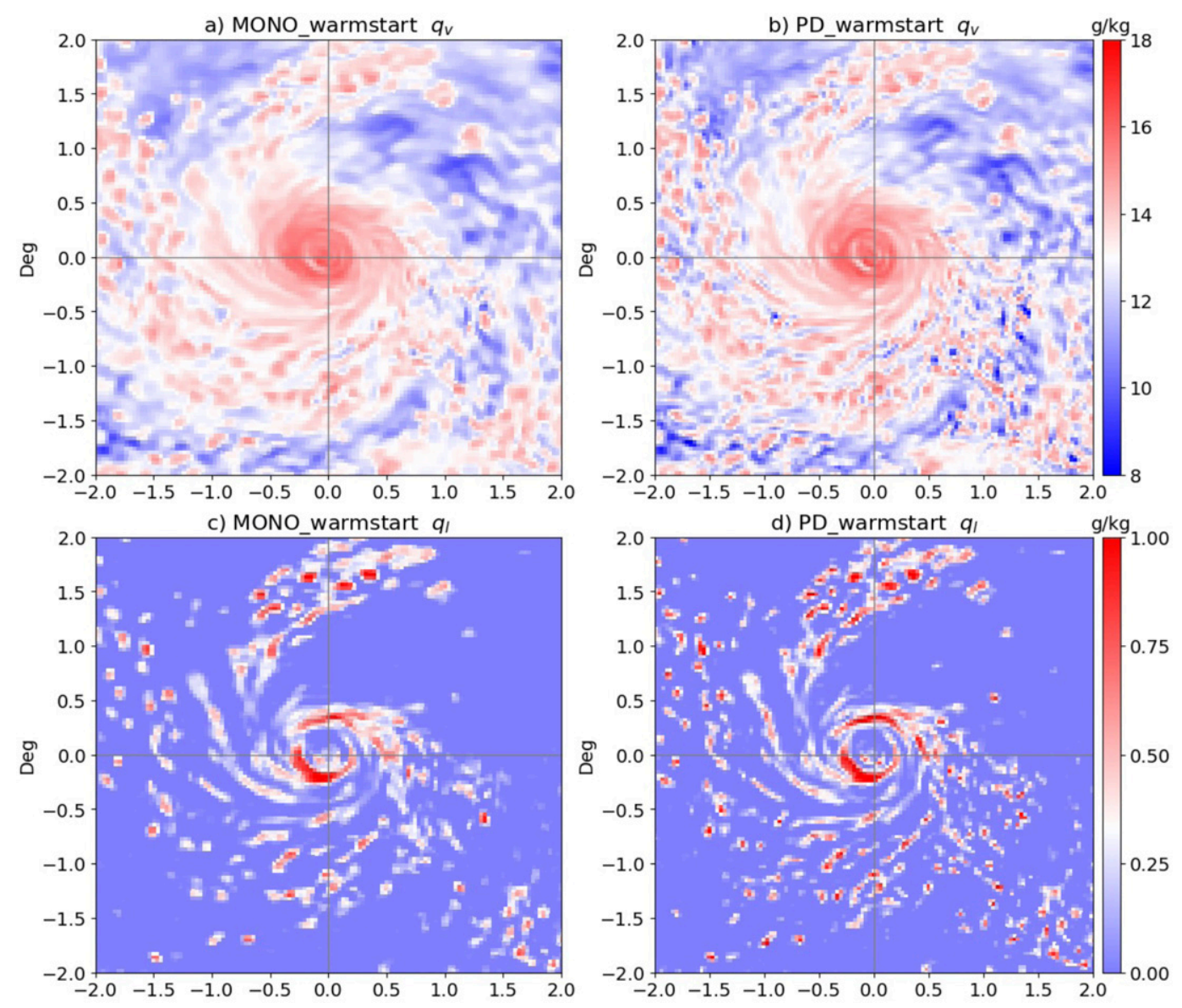

FIG. 8. Instantaneous tracer fields after $30 \mathrm{~min}$ of integration from the MONO_warmstart and PD_warmstart experiments. (a),(b) Specific humidity at $850 \mathrm{hPa}$. (c),(d) Liquid water mixing ratio at $850 \mathrm{hPa}$.

runs (Fig. 11c) indeed shows a dipole pattern below about $700 \mathrm{hPa}$ in the area of strong heating release (indicated by the diabatic heating contours), which appears to be consistent with that of $\delta \mathrm{H}$ (Fig. 9c). However, at higher levels there is no apparent enhancement of $q_{v}$ in PD_warmstart experiments in the area where $H$ is enhanced. This could be because any excessive moisture would be converted to cloud condensate above the condensation level in the warm-start runs. Also, it remains unclear if the negative change in $q_{v}$ in the eye region (Fig. 11c) is directly related to the choice of tracer advection scheme. We address this question next.

The result from the passive tracer experiments (Figs. 11df) helps interpret the pattern of $\delta q_{v}$. Note the horizontal and vertical winds are kept identical in PD_passive and MONO_ passive experiments. Thus, the difference in the $q_{v}$-like passive tracer between the two experiments can directly reveal the change of tracers resulting from the different diffusion property of the two tracer advection schemes. There is indeed considerable difference in the $q_{v}$-like passive tracer distribution along the radial-height cross section (Fig. 11f). The largest difference in $q_{v}$-like passive tracer distribution is in the lower levels (below $700 \mathrm{hPa}$ ), and the pattern is overall similar to that in the actual (interactive) $q_{v}$ field (Fig. 11c). The negative change of $q_{v}$-like passive tracer in the vicinity of the eye is consistent with that in the actual $q_{v}$ field (Fig. 11c), confirming that the use of PD scheme reduces the lower-level moisture content near the eye, presumably due to less diffusion into the storm center. The most important feature in Fig. 11f is that in the region with significant latent heating release (shown by the contours), the change of $q_{v}$-like passive tracer shows a dipole pattern that is consistent with $\delta H$ (Fig. 9c), confirming that the change of moisture content (and the associated conversion into cloud condensates) due to the choice of tracer advection scheme is at least partially responsible for the radial shift of the diabatic heating.

The above analysis provides a simplified view of how the tracer advection scheme affects the radial location of the diabatic heating. One can expect a lot of closely coupled microphysical processes are involved, and the change of $W$ (Fig. 9f) could positively feed back onto the change of $H$ (Fig. 9c). Nevertheless, the 30-min warm-start experiments indicate that the difference in implicit diffusion of moisture in the inner-core region is likely the key factor for driving the difference in the radial location of eyewall convection 

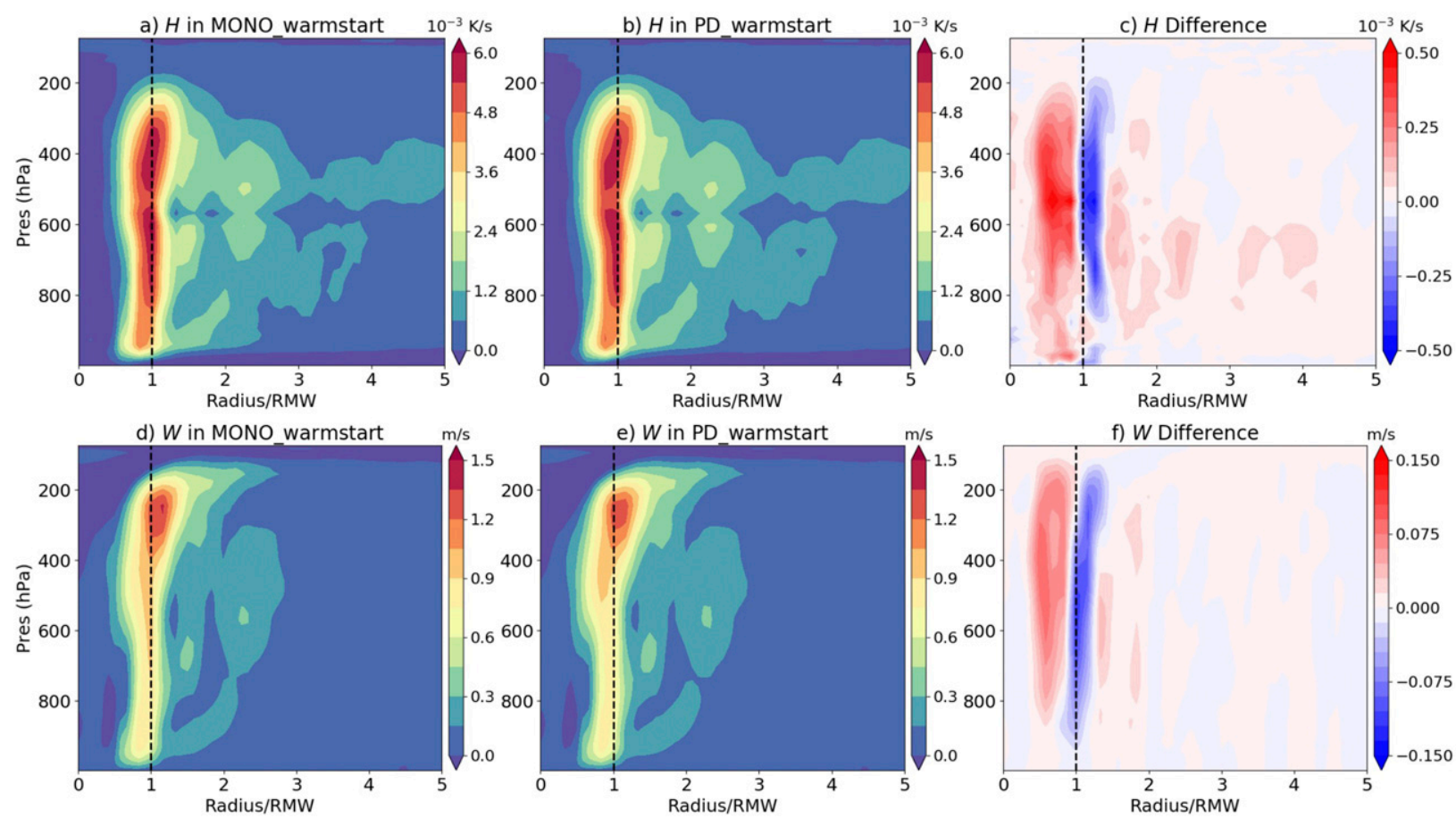

FIG. 9. (a),(b) Composite of diabatic heating $(H)$ from GFDL microphysics scheme time-averaged during the 30-min integration of the two warm-start experiments. (c) Composite of the difference between the two experiments (PD_warmstart minus MONO_ warmstart). (d)-(f) As in (a)-(c), but for the vertical velocity (W). The composite-mean RMWs are the same in the two sets of runs, which is $21.5 \mathrm{~km}$.

(diabatic heating and updraft) between the simulations using MONO and PD schemes, and the subsequent hurricane intensity changes.

\section{Summary}

We have presented an analysis of the sensitivity of hurricane intensity and eyewall convection structure to the horizontal tracer advection algorithm in the GFDL FV3 dynamical core. We compared two horizontal tracer advection schemes often used in FV3 applications, the monotonic (MONO) scheme that prevents spurious oscillations, and a less diffusive positivedefinite (PD) scheme. Through a selection of 5-day forecasts focusing on the prediction of the intensification of six major hurricanes, we find that the choice of horizontal tracer advection scheme has a major impact on the intensity prediction skill. The hurricanes in the forecasts using the PD scheme overall have stronger intensification rates and eventually reached stronger lifetime maximum intensity. The mean intensity bias and error in the PD forecasts are significantly reduced (at least $50 \%$ ) at lead times beyond the first $24 \mathrm{~h}$ compared with the MONO forecasts.

Notable storm structural differences are present in the two experiments. The hurricanes, in particular the major hurricanes, develop smaller eye size, as indicated by the radius of maximum wind (RMW), in the PD forecasts. The averaged RMW of storms with intensity stronger than $50 \mathrm{~m} \mathrm{~s}^{-1}$ in PD forecasts is about $30 \%$ smaller than those in MONO forecasts.
Moreover, there is a clear difference in the radial location of eyewall convection relative to the RMW in the two sets of experiments: the eyewall convection is located farther inside of the RMW in the PD forecasts. The higher inertial stability in the inner-core region (largely due to the smaller RMW) and the more radially inward eyewall convection in PD forecasts act in concert to support more rapid storm intensification.

We further confirm that the radial shift of the eyewall convection is a direct response to the choice of tracer advection scheme via a series of controlled 30-min-duration warm-start experiments that are initialized with fully spun-up hurricane dynamical and cloud hydrometer fields. When the PD advection scheme is used, the diabatic heating preferentially locates farther inward relative to the RMW. The change of water vapor distribution in the eyewall convection region resulting from the use of different horizontal tracer advection schemes is consistent with the pattern of the diabatic heating change, indicating that the tracer advection scheme affects the radial location of diabatic heating via affecting the inner-core moisture distribution.

The use of the less diffusive positive definite tracer advection scheme favors stronger storm intensity and plays a critical role in improving the intensity prediction of the major hurricanes considered in this study. Our results seem to be consistent with the previous studies (Bryan 2012; Zhang and Marks 2015) showing that weaker parameterized horizontal diffusion favors stronger storm intensity, although the underlying mechanisms are likely not the same. However, it should be noted that we do 

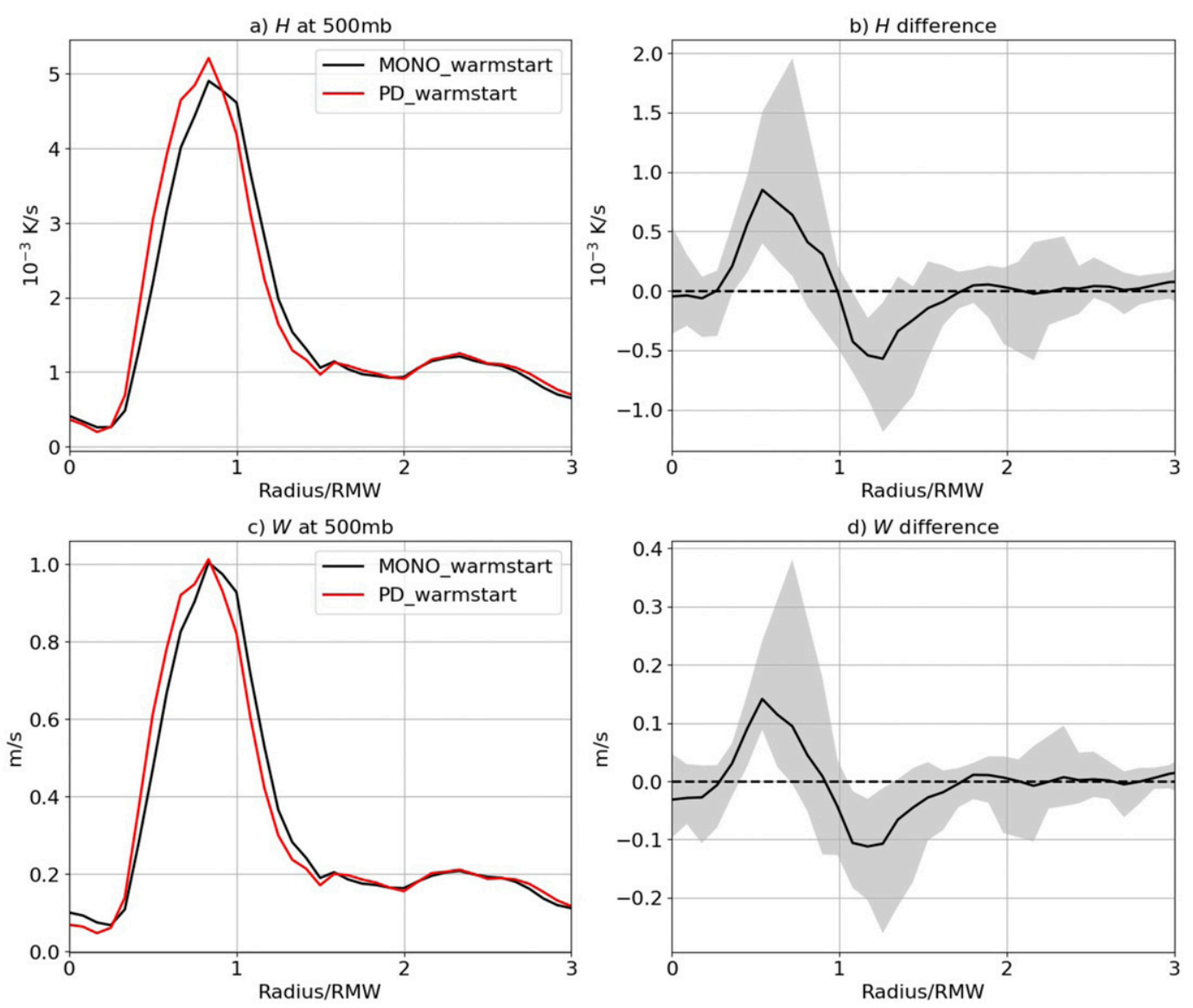

FIG. 10. (a) Composite diabatic heating profiles at $500 \mathrm{hPa}$ (30-min averaged) from the two warm-start experiments. (b) The composite difference of diabatic heating at $500 \mathrm{hPa}$; the gray area shows the range of individual difference profiles before the composite averaging. (c),(d) As in (a) and (b), but for the vertical velocity at $500 \mathrm{hPa}$.

not claim that the PD scheme is the only key ingredient for a skillful hurricane prediction system, nor that the PD scheme is a superior choice than the MONO scheme under all conditions. Although the use of MONO scheme underpredicts hurricane intensity, the hurricane inner-core size and composite structure from those 5-day forecasts still seem reasonable. Moreover, there could be other pathways through which the tracer advection scheme affects the hurricane intensity other than the eyewall convection. We observed noticeable differences in the outer-core convection activity in the two sets of 5-day forecasts, which may affect hurricane intensity and warrants future study. Also, our present test set mostly consists of RI cases. Further study should include a comprehensive evaluation of the impact of the two tracer advection schemes on the model intensity skill and consider a broad range of cases (intensifying, rapidly intensifying, steady state, and weakening), as well as comparison with other operational hurricane forecast models.

We emphasize here the significant impact of the horizontal tracer advection scheme on hurricane intensity prediction, which has not been recognized previously. Although the impact of various subgrid physical parameterizations on simulated hurricane characteristics has been well acknowledged and studied, the sensitivity of hurricane intensity prediction to the dynamical core algorithms (i.e., algorithms dealing with the gridscale flow) has not received as much attention. This study shows an example that the dynamicalcore algorithm can have significant impact on hurricane intensity and eyewall structure. Since FV3 is currently used as the dynamical core for many forecast models, including the operational Global Forecast System (GFS) and the forthcoming Hurricane Analysis and Forecast System (HAFS), this study should serve as a useful reference for developers and users of these and other FV3-based models for hurricane research and prediction.

Acknowledgments. The authors thank Shian-Jiann Lin for developing the positive definite advection scheme in FV3; Steve Garner, Timothy Marchok, and Xiaqiong Zhou for the discussions during the preparation of this manuscript; Jan-Huey Chen for developing and sharing with the authors with the TC verification tools with significance test capacity; 

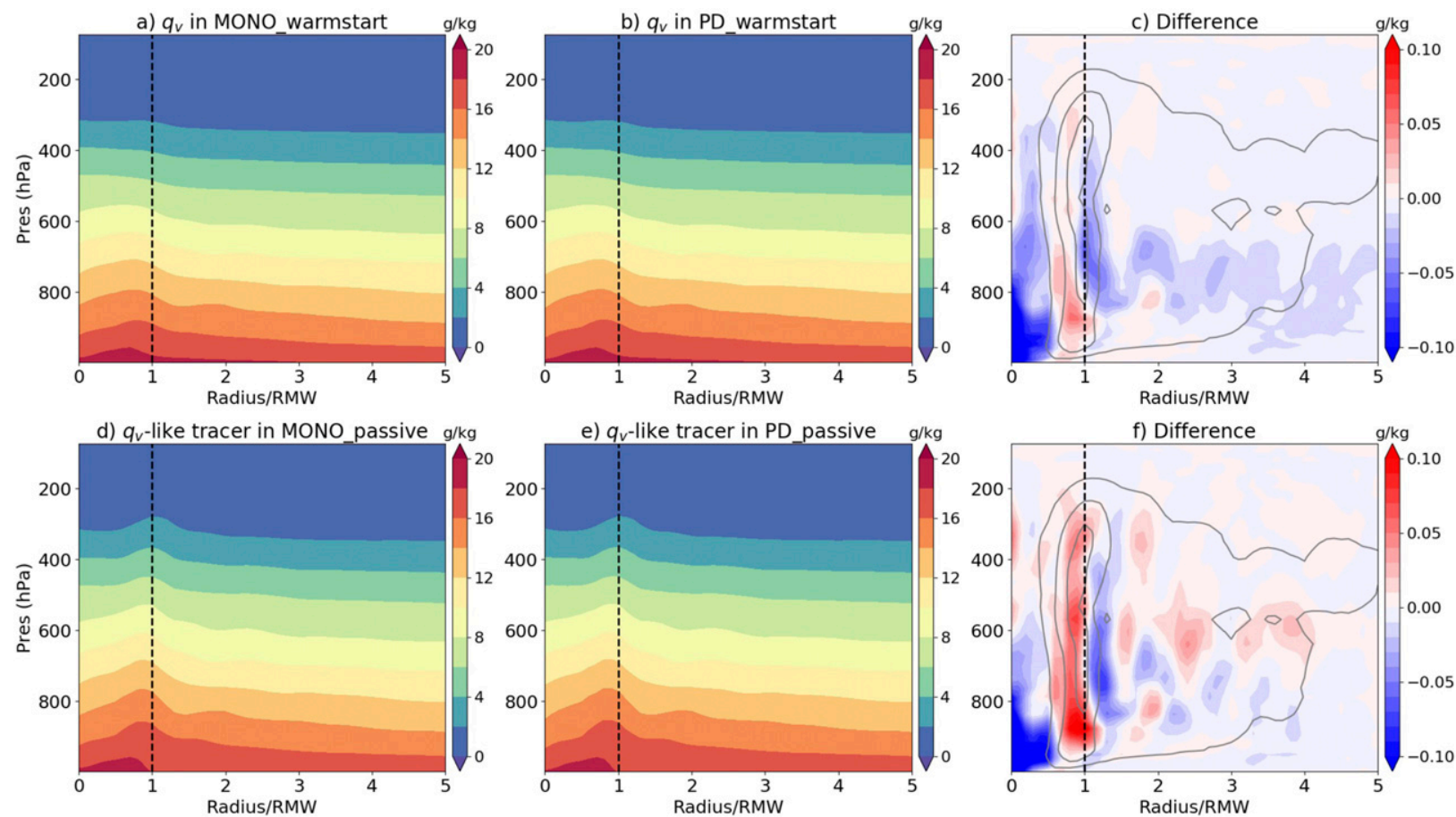

FIG. 11. (a),(b) Composite of specific humidity $\left(q_{v}\right)$ averaged during the 30-min integration of the two warm-start experiments. (c) Composite of the difference between the two (PD_warmstart minus MONO_warmstart). (d)-(f) As in (a)-(c), but for the $q_{v}$-like passive tracer from the passive tracer experiments. Note that the hurricane flow (both horizontal and vertical) is identical in MONO_passive and PD_passive experiments. The gray contours in (c) and (f) show the composite of diabatic heating from the PD_warmstart experiments to indicate the region with significant latent heat release (contours of $0.5,2.5$ and $5 \times$ $10^{-3} \mathrm{~K} \mathrm{~s}^{-1}$ are shown).

Andrew Hazelton for his contribution in the development of previous versions of T-SHiELD (formerly named hfvGFS) and earlier experiments comparing the two tracer advection schemes that inspired this manuscript; and James Huff for preparing the operational GFS analyses for initializing the model. This research was supported under Award
NA18OAR4320123 from the National Oceanic and Atmospheric Administration (NOAA), U.S. Department of Commerce. The statements, findings, conclusions, and recommendations are those of the authors and do not necessarily reflect the views of the National Oceanic and Atmospheric Administration or the U.S. Department of Commerce. a) MONO

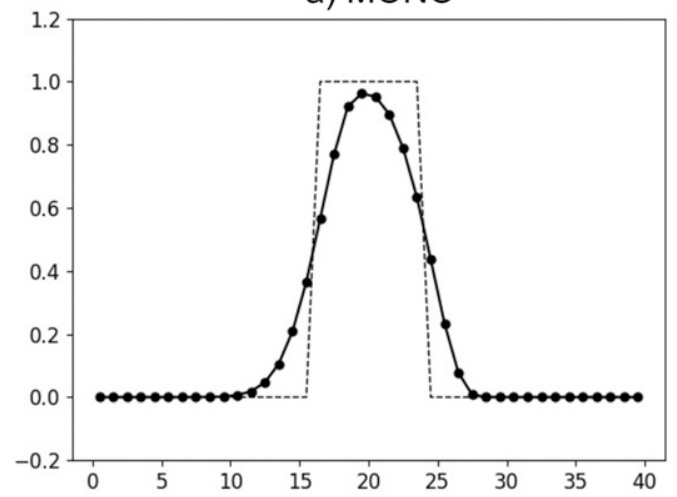

b) PD

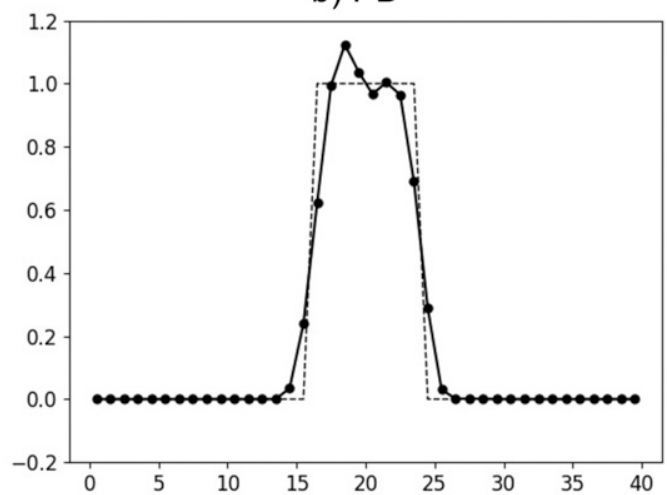

FIG. A1. (a) The transport of a rectangular wave in a 40-cell periodic domain $(d x=1.0)$ by the monotonic scheme. Courant number is 0.8 . The dashed line represents the initial wave. The solid line represents the numerical solution after the wave propagated back to its initial position (50 time steps). (b) As in (a), but for the positive-definite scheme. 


\section{APPENDIX}

\section{One-Dimensional Tests with the Monotonic and Positive-Definite Advection Schemes}

The mathematical details of MONO and PD schemes are described in Lin (2004, appendix B) and Harris et al. (2020, appendix A), respectively. Here we present results (Fig. A1) from simple one-dimensional advection tests initialized with rectangular wave signal. The purpose is to support our claim in the main text that the PD scheme is less diffusive than the MONO scheme.

\section{REFERENCES}

Bao, J.-W., S. G. Gopalakrishnan, S. A. Michelson, F. D. Marks Jr., and M. T. Montgomery, 2012: Impact of physics representations in the HWRFX on simulated hurricane structure and pressure-wind relationships. Mon. Wea. Rev., 140, 3278-3299, https://doi.org/10.1175/MWR-D-11-00332.1.

Bryan, G. H., 2012: Effects of surface exchange coefficients and turbulence length scales on the intensity and structure of numerically simulated hurricanes. Mon. Wea. Rev., 140, 11251143, https://doi.org/10.1175/MWR-D-11-00231.1.

Chen, J. H., and Coauthors, 2019: Advancements in hurricane prediction with NOAA's next-generation forecast system. Geophys. Res. Lett., 46, 4495-4501, https://doi.org/10.1029/ 2019GL082410.

Colella, P., and P. R. Woodward, 1984: The piecewise parabolic method (PPM) for gas-dynamical simulations. J. Comput. Phys., 54, 174-201, https://doi.org/10.1016/0021-9991(84) 90143-8.

Gao, K., L. Harris, J.-H. Chen, S.-J. Lin, and A. Hazelton, 2019: Improving AGCM hurricane structure with two-way nesting. J. Adv. Model. Earth Syst., 11, 278-292, https://doi.org/ 10.1029/2018MS001359.

Gopalakrishnan, S. G., S. Goldenberg, T. Quirino, F. D. Marks Jr., X. Zhang, K.-S. Yeh, R. Atlas, and V. Tallapragada, 2012: Toward improving high-resolution numerical hurricane forecasting: Influence of model horizontal grid resolution, initialization, and physics. Wea. Forecasting, 27, 647-666, https:// doi.org/10.1175/WAF-D-11-00055.1.

—, F. D. Marks Jr., J. A. Zhang, X. Zhang, J.-W. Bao, and V. Tallapragada, 2013: A study of the impacts of vertical diffusion on the structure and intensity of the tropical cyclones using the high-resolution HWRF system. J. Atmos. Sci., 70, 524-541, https://doi.org/10.1175/JAS-D-11-0340.1.

Han, J., W. Wang, Y. C. Kwon, S. Hong, V. Tallapragada, and F. Yang, 2017: Updates in the NCEP GFS cumulus convection schemes with scale and aerosol awareness. Wea. Forecasting, 32, 2005-2017, https://doi.org/10.1175/WAFD-17-0046.1.

Harris, L. M., and S.-J. Lin, 2013: A two-way nested global-regional dynamical core on the cubed-sphere grid. Mon. Wea. Rev., 141, 283-306, https://doi.org/10.1175/MWR-D-11-00201.1.

,-- , and C. Y. Tu, 2016: High resolution climate simulations using GFDL HiRAM with a stretched global grid. J. Climate, 29, 4293-4314, https://doi.org/10.1175/JCLI-D-15-0389.1.

— weather-to-seasonal prediction. J. Adv. Model. Earth Syst., 12, e2020MS002223, https://doi.org/10.1029/2020MS002223.

Hong, S.-Y., Y. Noh, and J. Dudhia, 2006: A new vertical diffusion package with an explicit treatment of entrainment processes.
Mon. Wea. Rev., 134, 2318-2341, https://doi.org/10.1175/ MWR3199.1.

Iacono, M. J., J. S. Delamere, E. J. Mlawer, M. W. Shephard, S. A. Clough, and W. D. Collins, 2008: Radiative forcing by longlived greenhouse gases: Calculations with the AER radiative transfer models. J. Geophys. Res., 113, D13103, https://doi.org/ 10.1029/2008JD009944.

Kepert, J. D., 2001: The dynamics of boundary layer jets within the tropical cyclone core. Part I: Linear theory. J. Atmos. Sci., 58, 2469-2484, https://doi.org/10.1175/1520-0469(2001)058<2469: TDOBLJ $>2.0 . \mathrm{CO} ; 2$.

_ 2017: Time and space scales in the tropical cyclone boundary layer, and the location of the eyewall updraft. J. Atmos. Sci., 74, 3305-3323, https://doi.org/10.1175/JAS-D-17-0077.1.

_ the boundary layer contribute to eyewall replacement cycles in axisymmetric tropical cyclones?"' J. Atmos. Sci., 71, 46924704, https://doi.org/10.1175/JAS-D-14-0014.1.

Landsea, C. W., and J. L. Franklin, 2013: Atlantic hurricane database uncertainty and presentation of a new database format. Mon. Wea. Rev., 141, 3576-3592, https://doi.org/ 10.1175/MWR-D-12-00254.1.

Lin, S.-J., 2004: A “vertically Lagrangian" finite-volume dynamical core for global models. Mon. Wea. Rev., 132, 22932307, https://doi.org/10.1175/1520-0493(2004)132<2293: AVLFDC $>2.0 . \mathrm{CO} ; 2$.

— , and R. Rood, 1996: Multidimensional flux-form semiLagrangian transport schemes. Mon. Wea. Rev., 124, 20462070, https://doi.org/10.1175/1520-0493(1996)124<2046: MFFSLT $>2.0 . \mathrm{CO} ; 2$.

McFarquhar, G. M., H. Zhang, G. Heymsfield, R. Hood, J. Dudhia, J. B. Halverson, and F. Marks Jr., 2006: Factors affecting the evolution of Hurricane Erin (2001) and the distributions of hydrometeors: Role of microphysical processes. J. Atmos. Sci., 63, 127-150, https://doi.org/10.1175/JAS3590.1.

Pollard, R. T., P. B. Rhines, and R. O. R. Y. Thompson, 1973: The deepening of the wind-mixed layer. Geophys. Fluid Dyn., 3, 381-404, https://doi.org/10.1080/03091927208236105.

Putman, W., and S.-J. Lin, 2007: Finite-volume transport on various cubed-sphere grids. J. Comput. Phys., 227, 55-78, https:// doi.org/10.1016/j.jcp.2007.07.022.

Rogers, R., P. Reasor, and S. Lorsolo, 2013: Airborne Doppler observations of the inner-core structural differences between intensifying and steady-state tropical cyclones. Mon. Wea. Rev., 141, 2970-2991, https://doi.org/10.1175/MWR-D12-00357.1.

Rotunno, R., and G. H. Bryan, 2012: Effects of parameterized diffusion on simulated hurricanes. J. Atmos. Sci., 69, 22842299, https://doi.org/10.1175/JAS-D-11-0204.1.

Schubert, W. H., and J. J. Hack, 1982: Inertial stability and tropical cyclone development. J. Atmos. Sci., 39, 1687-1697, https://doi.org/10.1175/1520-0469(1982)039<1687:ISATCD> 2.0.CO;2.

Shapiro, L. J., and H. E. Willoughby, 1982: The response of balanced hurricanes to local sources of heat and momentum. J. Atmos. Sci., 39, 378-394, https://doi.org/10.1175/15200469(1982)039<0378:TROBHT>2.0.CO;2.

Smith, R. K., and M. T. Montgomery, 2016: The efficiency of diabatic heating and tropical cyclone intensification. Quart. J. Roy. Meteor. Soc., 142, 2081-2086, https://doi.org/10.1002/ qj.2804.

, - _ and G. L. Thomsen, 2014: Sensitivity of tropical cyclone models to the surface drag coefficient in different boundary 
layer schemes. Quart. J. Roy. Meteor. Soc., 140, 792-804, https://doi.org/10.1002/qj.2057.

Vigh, J., and W. H. Schubert, 2009: Rapid development of the tropical cyclone warm core. J. Atmos. Sci., 66, 3335-3350, https://doi.org/10.1175/2009JAS3092.1.

Willoughby, H. E., H.-L. Jin, S. J. Lord, and J. M. Piotrowicz, 1984: Hurricane structure and evolution as simulated by an axisymmetric, nonhydrostatic numerical model. J. Atmos. Sci., 41, 1169-1186, https://doi.org/10.1175/1520-0469(1984) $041<1169$ :HSAEAS $>2.0$. CO; 2 .

Zhang, J. A., and F. D. Marks, 2015: Effects of horizontal diffusion on tropical cyclone intensity change and structure in idealized three-dimensional numerical simulations. Mon. Wea. Rev., 143, 3981-3995, https://doi.org/10.1175/MWR-D14-00341.1.

_- D. S. Nolan, and R. F. Rogers, 2015: Evaluating the impact of improvements in the boundary layer parameterization on hurricane intensity and structure forecasts in HWRF. Mon. Wea. Rev., 143, 3136-3155, https://doi.org/ 10.1175/MWR-D-14-00339.1.

Zhou, L., S.-J. Lin, J.-H. Chen, L. M. Harris, X. Chen, and S. L. Rees, 2019: Toward convective-scale prediction within the Next Generation Global Prediction System. Bull. Amer. Meteor. Soc., 100, 1225-1243, https://doi.org/10.1175/BAMS-D-17-0246.1. 